\title{
Mammals in Danger of Extinction
}

\begin{abstract}
NE of the requests most often asked of the FPS is for a list of mammals threatened by extinction. The full list, included as a supplement to the April Bulletin of IUCN, contains 214 species and subspecies, about many of which we have very little information. We are therefore reproducing here the selected list prepared for the Zoos and Conservation Symposium (see p. 215), which contains the thirty-one species classified by the Survival Service Commission of the IUCN as "very rare and believed to be decreasing in numbers". These include seventeen "three-star" species which are "giving cause for very grave anxiety", and fourteen "two-star" species which are " giving cause for considerable anxiety". Those marked " $P$ " have at least some protection. The main source of information is IUCN's Red Data Book (see ORYX, VII, 4, p. 158). Details of numbers in zoos come from the International Zoo Yearbook, Vol. IV.
\end{abstract}

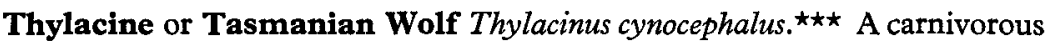
marsupial, in very small numbers in a few widely separated localities in western Tasmania.

Coquerel's Dwarf or Mouse Lemur Microcebus coquereli. $\star \star$ Reliably reported only from one locality in south-western Madagascar.

Indri Indri indri. $\star \star \star$ A large lemur with a restricted range in the eastern mountains of Madagascar, decreasing with the loss of natural forest.

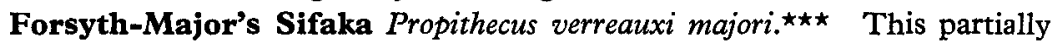
melanistic race is the most localised and the most seriously threatened of the sifaka lemurs, occurring in the Sakaraha Forest of Madagascar.

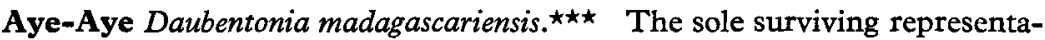
tive of the remarkable and aberrant lemur family Daubentoniidae, now extremely rare with a restricted range in the eastern and north-western coastal forests of Madagascar.

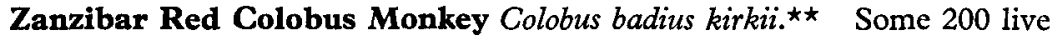
in groups of six or seven scattered over the eastern bush country of Zanzibar, which is largely uninhabited, as well as in the Jozani Forest Reserve. Two males in Frankfurt Zoo.

Orang-utan Pongo pygmaeus. $\star \star \star$ A rapidly decreasing population of 5,000 to 6,000 survive in limited areas of the Borneo and Sumatra jungles; 280 in ninety-two zoos; 13 males and 15 females bred in captivity.

Black-footed Ferret Mustela nigripes. $\star \star$ Once believed to be extinct, but a few were seen in South Dakota in 1955 and limited numbers may exist elsewhere in North America. Four males and two females in four zoos.

Spanish Lynx Felis lynx pardina. ${ }^{\star}$ A few hundred only remain in the southern half of the Iberian Peninsula, including 150 to 200 in the Coto Donana. One pair in captivity in Paris.

The World's Five Species of Rhinoceros

From left to right: the great Indian; the Javan; the Sumatran ; the black; the square-lipped (white). The figures underneath each are the estimated populations in 1963 ; in 1964 the Javan rhino figure of 30 is believed to have been reduced to 20 . The drawing is from the notepaper of the Rhinoceros Group of the Survival Service Commission.

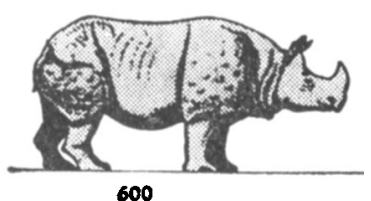

600 


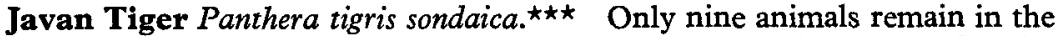
wild, all in the Udjong Kulon peninsula, Java. Two males and five females in four zoos; one female bred in captivity.

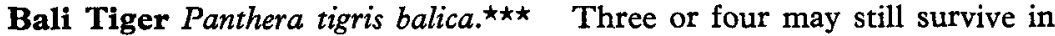
the extreme west of Bali.

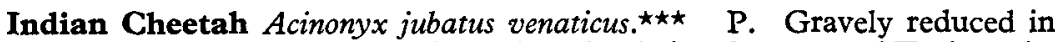
both numbers and range, and now found only in a few parts of Turkmenia, Iran and possibly Afghanistan. Five males and three females in five zoos, but some of these may in fact be African cheetahs.

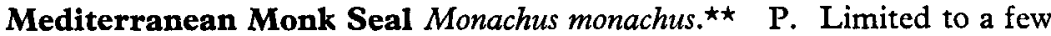
colonies in the Mediterranean and Black Sea, with one in North-west Africa, totalling 1,000 to 5,000. Two in two zoos.

Caribbean Monk Seal Monachus tropicalis. ${ }^{\star \star \star}$ Almost extinct but may still occur in Jamaican waters.

Persian Wild Ass Equus hemionus onager. $\star \star \quad P$. Now exists only in parts of Iran, where believed to number about 300 . At least seventy-two in twenty zoos; at least nineteen bred in captivity.

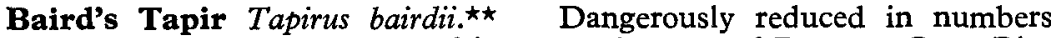
throughout the greater part of its range, in parts of Panama, Costa Rica and Mexico. Four males and three females in four zoos; at least one bred in captivity.

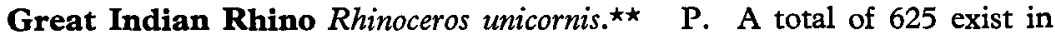
north-east India and the Rapti valley of Nepal. Sixteen males and four females in eighteen zoos. Four males and three females bred in captivity.

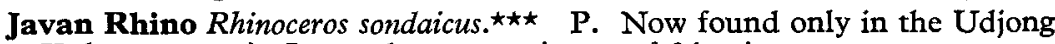
Kulon reserve in Java, where a maximum of 24 exist.

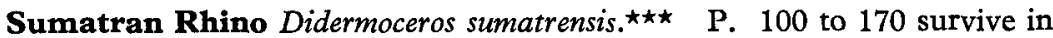
a few scattered localities in Burma, Malaya, Sumatra and Sabah. One female at Copenhagen Zoo.

Mesopotamian Fallow Deer Dama mesopotamica. $\star \star 200$ to 400 occupy a restricted area of about $200 \mathrm{sq} . \mathrm{km}$. along the Karcheh river, southwestern Iran, where they are threatened by the felling of forests for charcoal. One female in captivity at Kronberg Zoo.

Manipur Brow-antlered Deer Cervus eldi eldi. $\star \star$ P. About 100 survive in an area of $10 \mathrm{sq} . \mathrm{m}$. on the Logtak Lake, Manipur, India. Three males and nine females, all bred in captivity, in Paris.

Thailand Brow-antlered Deer Cervus eldi siamensis. $\star \star \star$ Only a few herds of four to five animals each survive in northern and north-eastern Thailand.

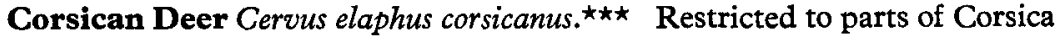
and Sardinia and now numbering fewer than 20.

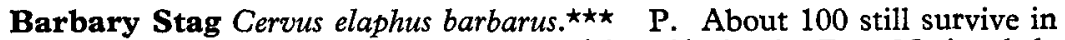
the cork forests of north-western Tunisia. Six in the Parc National de Bugeaud, Algeria.

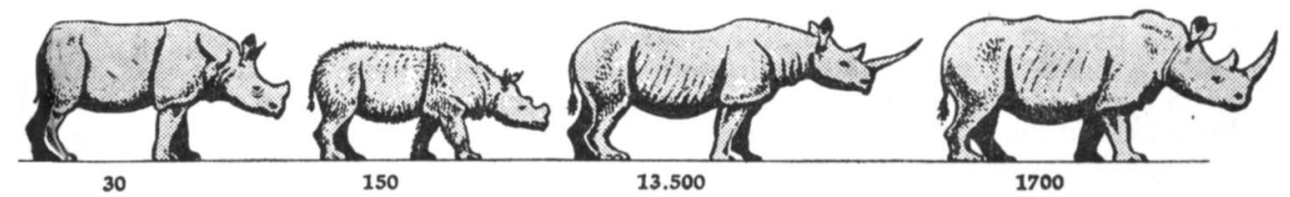




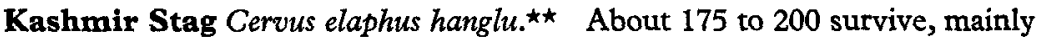
in the Dachigam sanctuary, with a few in other parts of Kashmir.

Kouprey Bos sauveli. $\star \star \star$ P. A forest ox, only discovered in 1937, restricted to two separate regions in northern Cambodia and numbering about 200 in all.

Seladang Bos gaurus hubbacki. $\star \star$ P. A wild ox occurring in the Malay Peninsula, mainly in Pahang State, and now reduced to about 300.

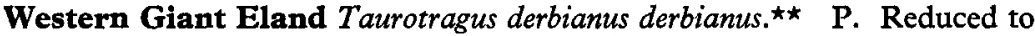
a few dozen animals in the interior of Guinea and the Ivory Coast.

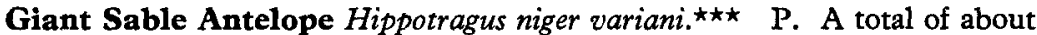
500 to 700 occupy the Luando Reserve and the Cangandala area in Angola.

Arabian Oryx Oryx leucoryx. ${ }^{\star \star}$ P. Still occurs in some of the remoter parts of Muscat and Oman, where may number 200 to 300, but no longer in the Eastern Arabian Protectorate. Eleven at Phoenix Zoo, Arizona, of which five belong to the Fauna Preservation Society, four to the World Wildlife Fund and two to the Zoological Society of London; eleven in two zoos in Saudi Arabia. Breeds readily in captivity; four born at Riyadh Zoo and two at Phoenix during past two years.

Walia Ibex Capra walie. ${ }^{\star \star}$ Possibly 200 inhabit the Simien plateau, Ethiopia.

\section{MUST THE FIN WHALE BE EXTERMINATED?}

THE outcome of the International Whaling Commission Meeting in Norway in June, though satisfactory for the conservation of blue and humpback whales, was disastrous for the Antarctic populations of the fin and sei whales. Owing to complete disagreement among the countries represented, no official agreement as to catch limits was reached at all. The Committee of Four Scientists had recommended a phased reduction of catches, of 4,000 blue whale units in 1964-65,3,000 in 1965-66 and 2,000 in $1967-68$, in order to allow recovery of stocks to begin in 1966-67. * Although the four Antarctic pelagic whaling countries (Russia, Japan, Norway, Holland) conferred together outside the conference and agreed a catch limit of 8,000 blue whale units (double the recommended number), conservationists are bound to take the most serious view of this flouting of scientific advice. This is perhaps the first time in history that four Governments have deliberately set out on a course of action that they know is likely to result in the extermination of at least one species of animal, the fin whale. Catches of fin whales in the Antarctic fell from 18,868 in 1962-63 to 13,870 in 1963-64, and are clearly likely to fall still further in 1964-65. Indeed, it looks as if the whaling industry has decided to cash in on the remaining stocks and then abandon whaling altogether, instead of taking the civilised decision to conserve stocks so that whaling can continue into the future. It is not surprising that the work of the Committee of Four Scientists in collaboration with FAO is likely to be suspended this year. There is little point in wasting scientists' time like this. A grave situation is also building up in the North Pacific, and it seems too much to hope that sanity will prevail there, when it has not done so in the Antarctic. Two welcome decisions were, however, made by the IWC, to extend complete protection to the blue whale south of $40^{\circ} \mathrm{S}$., and to continue for another five years the complete protection of the humpback in the southern hemisphere.

$\star$ One blue whale unit $=2$ fin or $2 \frac{1}{2}$ humpback or 6 sei whales. 